Marquette University

e-Publications@Marquette

Chemistry Faculty Research and Publications

Chemistry, Department of

$5-1-2006$

\title{
Characterization of the Transition State of Functional Enzyme Dynamics
}

Evgueni Kovriguine

Marquette University, evgueni.kovriguine@marquette.edu

J. Patrick Loria

Yale University

Accepted version. Journal of the American Chemical Society, Vol. 128, No. 24 (May 2006): 7724-7725.

DOI. (C) 2006 American Chemical Society. Used with permission. 


\title{
Characterization of the Transition State of Functional Enzyme Dynamics
}

\author{
Evgenii L. Kovrigin \\ Department of Chemistry, Yale University, \\ New Haven, $C T$ \\ J. Patrick Loria \\ Department of Chemistry, Yale University, \\ New Haven, CT
}




\section{Abstract}

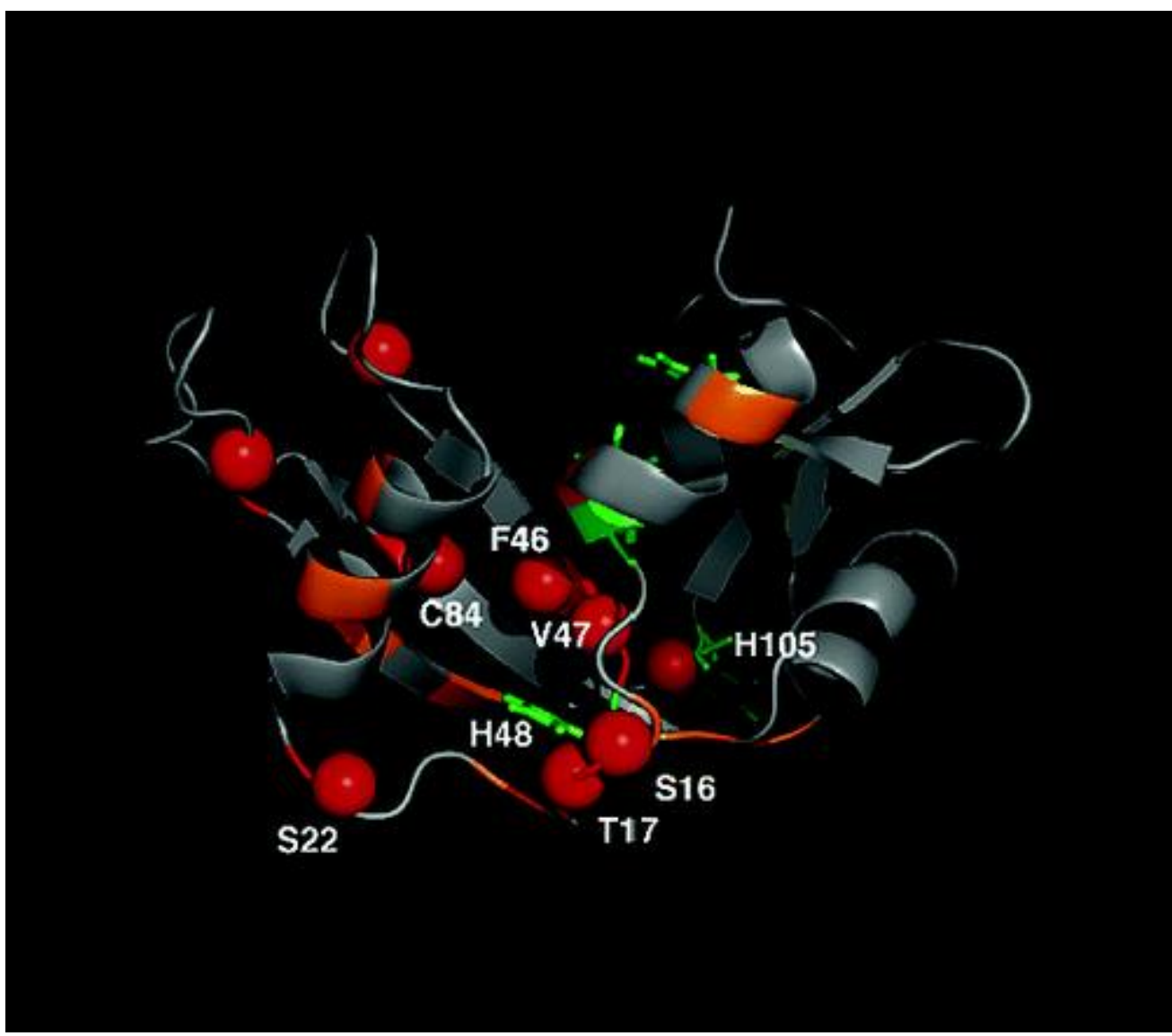

Through characterization of the solvent isotope effect on protein dynamics, we have examined determinants of the rate limitation to enzyme catalysis. A global conformational change in Ribonuclease $A$ limits the overall rate of catalytic turnover. Here we show that this motion is sensitive to solvent deuterium content; the isotope effect is 2.2 , a value equivalent to the isotope effect on the catalytic rate constant. We further demonstrate that the protein motion possesses a linear proton inventory plot, indicating that a single proton is transferred in the transition state. These results provide compelling evidence for close coupling between enzyme dynamics and function and demonstrate that characterization of the transition state for protein motion in atomic detail is experimentally accessible.

In many enzyme-catalyzed reactions, evolution has optimized the chemical steps such that protein conformational changes occurring in the microsecond-millisecond time regime are rate limiting to catalysis. ${ }^{1,2}$ Motions on this time scale are clearly of central importance to enzymatic activity, and recent experiments have illuminated the

Journal of the American Chemical Society, Vol 128, No. 24 (May 2006): pg. 7724-7725. DOI. This article is (C) American Chemical Society and permission has been granted for this version to appear in e-Publications@Marquette. American Chemical Society does not grant permission for this article to be further copied/distributed or hosted elsewhere without the express permission from American Chemical Society. 
intimate connection between these conformational changes and catalytic turnover. ${ }^{3-6}$ However, the mechanistic details of these motions are not fully known. Knowledge of these structural rearrangements is essential for the successful de novo design of catalysts, for optimization of enzyme-inhibitor interactions, for reengineering existing catalysts, and for a basic understanding of the physical chemistry involved in enzyme function. Time-averaged structures typically provide details of the endpoints of an enzyme reaction through three-dimensional characterization of enzyme-substrate or product complexes. However, these structures provide no information on the rates of these motions or the energy landscape that defines the pathway of conformational motion. The height of the energy barrier that separates the interconverting conformations determines the rate at which enzyme motion occurs. For a full understanding of the relation between function and protein motion, it is essential to uncover the principal determinants of this transition state. Here we examine factors that determine the transition state for motion through the effects of $\mathrm{D}_{2} \mathrm{O}$ on protein conformational exchange rates.

Characterization of the energy landscape that defines protein motion can be obtained using NMR spin-relaxation experiments to quantitate the kinetic and thermodynamic aspects of this motion. ${ }^{7,8}$ At its essence, a change between conformational states involves the breaking of interactions in one state and formation of new interactions in the final conformation. Changes in hydrogen bonding that occur in the transition state may be identified and characterized by measurement of the kinetic solvent isotope effect (KSIE) on the rate of enzyme motion. Ribonuclease A (RNase A) is an enzyme in which flexibility is important and rate limiting to catalysis; the slow step involves a protein conformational change that gates product release. ${ }^{9}$

RNase $A$ is an efficient catalyst, accelerating the cleavage of single-stranded RNA by $10^{11}$-fold over the uncatalyzed reaction. ${ }^{10}$ The rate-limiting conformational change that is responsible for product release involves several loop regions as well as residues at the active site. These loops include loop 4, which provides for specificity of purine binding $5^{\prime}$ to the site of bond cleavage, and loop 1 , which contains several flexible residues that are $>20 \AA$ from the enzyme active site. The motion of these protein regions is part of a pre-existing 
equilibrium between the free and bound conformation, indicating that RNase A samples the catalytically relevant conformations even in the absence of substrate. ${ }^{11}$ Previously, we have characterized the millisecond dynamics in the E, ES, and EP complexes and have shown that the conformational dynamics are unchanged in these different RNase $\mathrm{A} /$ ligand complexes and that these motions are rate limiting. $3,11,12$

These studies indicate that apo enzyme dynamics are functionally important as they reflect motions on the catalytic pathway. As expected for a rate-limiting conformational transition, the time scale of this motion at $298 \mathrm{~K}$ is $\sim 1700 \mathrm{~s}^{-1}$, the same as $k_{\text {cat }}$ and the product release rate. ${ }^{12}$ This dynamic process lies at the heart of RNase A enzymatic function, yet the types of interactions that determine the barrier separating these essential conformations are not known.

To address these questions, we determined the effects of substitution of $\mathrm{H}_{2} \mathrm{O}$ with $\mathrm{D}_{2} \mathrm{O}$ on the rate of protein dynamics under solution conditions in which RNase A possesses maximal catalytic activity. Replacement of $\mathrm{H}_{2} \mathrm{O}$ by $\mathrm{D}_{2} \mathrm{O}$ is one of the least perturbing methods, in terms of affecting protein structure and stability, and allows detailed insight into reaction mechanisms. At $\mathrm{pL}(\mathrm{L}=\mathrm{H}$ or $\mathrm{D})=$ 6.4 , the rate of the RNase $A$ catalyzed transphosphorylation reaction experiences a $\mathrm{KSIE}{ }^{\mathrm{H}} K_{\text {cat }} /{ }^{\mathrm{D}} K_{\text {cat }} \sim 2.0 .{ }^{13}$ This result indicates that a proton is relayed in the rate-determining transition state. Because RNA transphosphorylation chemistry is not rate limiting in the RNase A reaction, the observed isotope effect must be due to a decrease in the rate of conformational rearrangement of the enzyme. If the ratedetermining step to catalytic throughput is closely coupled to a protein conformational change, similar effects of deuterium substitution should be observed on the millisecond RNase A dynamics. Solution NMR CPMG-relaxation dispersion measurements ${ }^{7}$ were performed on RNase $A$ in solutions of $\mathrm{D}_{2} \mathrm{O}$ and $\mathrm{H}_{2} \mathrm{O}$ to assess the affects on protein dynamics.

These dynamic amino acid residues are located throughout the enzyme (Supporting Information), which highlights the global character of this conformational change. The CPMG dispersion data show a distinct dependence on the solvent deuterium content (Figure 1). Dispersion curves for all residues are provided in the Supporting 
Information. The conformational exchange rate, $k_{\mathrm{ex}}$, determined for all residues at two magnetic fields and $4.8 \% \mathrm{D}_{2} \mathrm{O}$ is $1810 \pm 90 \mathrm{~s}^{-1}$. This value decreases to $830 \pm 220 \mathrm{~s}^{-1}$ at $98 \% \mathrm{D}_{2} \mathrm{O}$. At intermediate values of $\mathrm{D}_{2} \mathrm{O}(33$ and $52 \%), k_{\mathrm{ex}}=1370 \pm 130$ and $1300 \pm 160 \mathrm{~s}^{-1}$, respectively. Identical behavior is observed for all exchanging residues, indicating a collective global process. This conformational motion in RNase A experiences a KSIE of $2.2 \pm 0.2$, which is within error of the effect on $k_{\text {cat }}$ of RNA cleavage. This suggests that motion in RNase $A$ is closely coupled to and limits the overall rate of catalytic turnover. This result is contrasted with proton inventory studies of the nonphysiological hydrolysis of cyclic mononucleotides. ${ }^{15}$

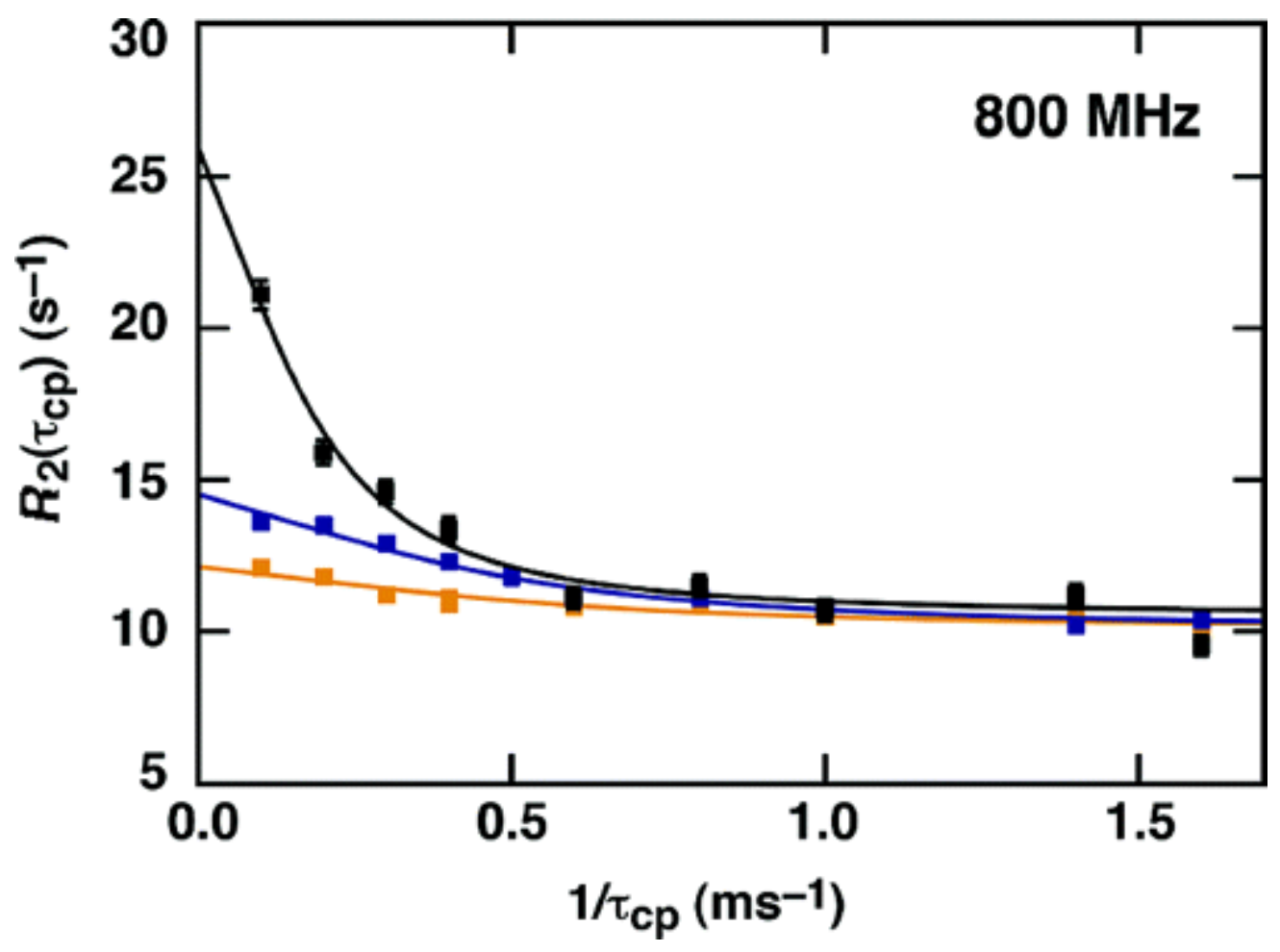

Figure 1 Relaxation dispersion data for the $\mathrm{C}^{\varepsilon}$ position of Met29 at $18.8 \mathrm{~T}$ for $4.8 \%$ (orange), 52\% (blue), and 98\% (black) $\mathrm{D}_{2} \mathrm{O}$. Dispersion curve fitting and statistical testing are as described previously. ${ }^{11}$ The fitted lines to the data points are the result of a global two-field fit to all residues. Experimental details are given as Supporting Information.

Together, these multi-residue, multi-field dispersion data produce a linear proton inventory plot for the conformational motion (Figure 2). ${ }^{14}$ Least-squares fitting with eq 1

$$
k_{n}=k_{0}\left(1-n+n \phi_{1}^{\mathrm{T}}\right)
$$


in which $k_{n}$ is the measured rate in $n$ atom fraction $\mathrm{D}_{2} \mathrm{O}, k_{0}$ is the rate in pure $\mathrm{H}_{2} \mathrm{O}$, and $\phi_{1}^{\mathrm{T}}$ is the transition state fractionation factor, which is an equilibrium constant describing the preference of ${ }^{2} \mathrm{H}$ at a protein site relative to that in solvent, yields $\phi_{1}^{T}=0.44 \pm 0.05$. The linearity of this proton inventory data suggests that a single proton is being transferred in the rate-limiting transition state. In addition, within the uncertainties of the measurements, the populations of the interconverting RNase A conformers do not vary significantly with solvent deuterium content (Figure 2 inset and Table S1).

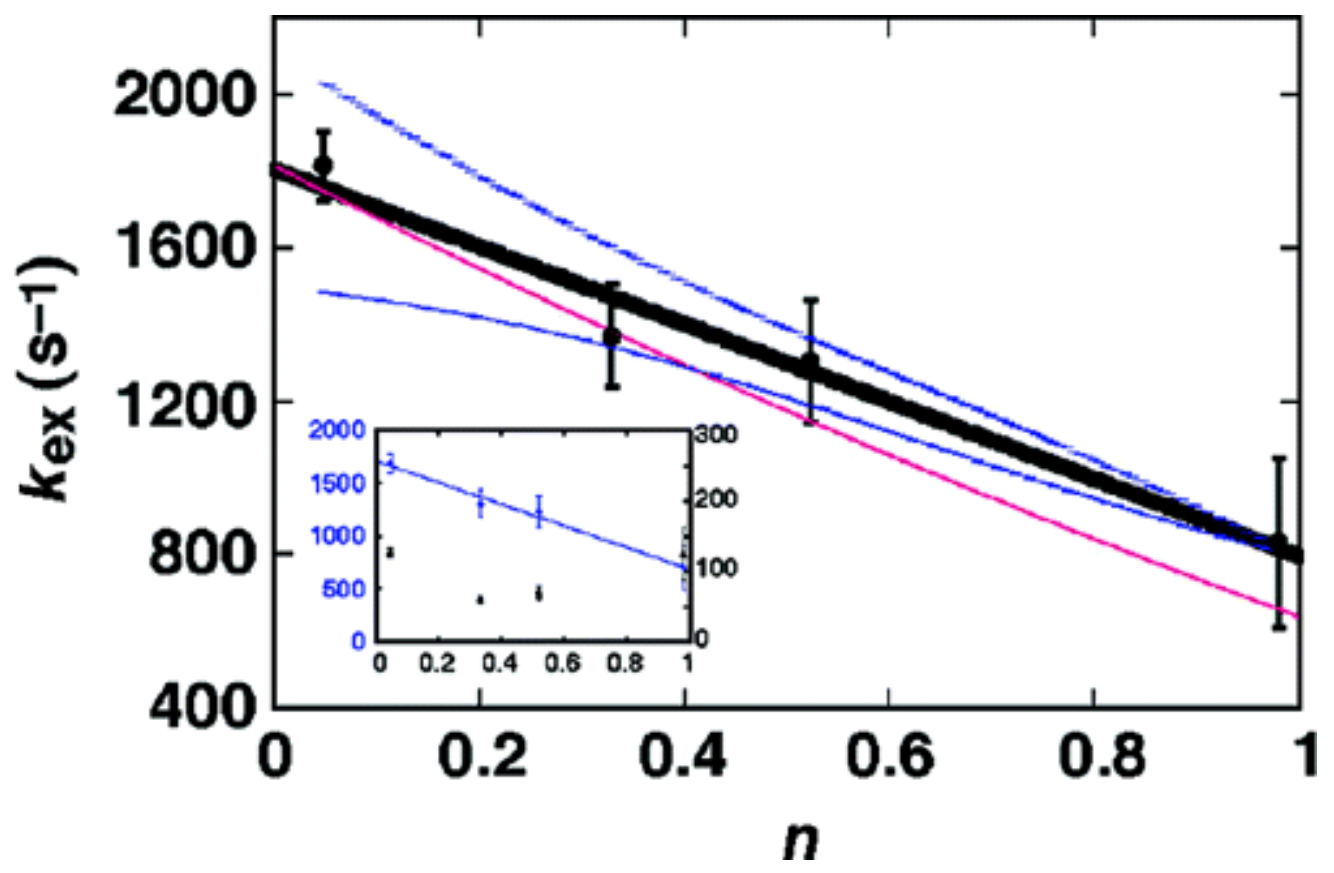

Figure 2 The proton inventory data for all residues participating in global motional dynamics at $n$ atom fraction of $\mathrm{D}_{2} \mathrm{O}$. The data points and error bars represent results of the global, two-field fit of the relaxation dispersion data. The black line represents the fit to the data with eq 1 , the blue lines are the $95 \%$ confidence intervals of the fit, and the red line depicts the theoretical curve for a two-proton transfer with identical fractionation factors and an overall isotope effect of 2.2. F-tests indicate eq 1 is statistically better than that for a two-proton mechanism. The inset shows the KSIE for the individual rate constants, $k_{1}$ and $k_{-1}$.

These data indicate that multiple amino acid residues located throughout the protein structure experience the same solvent isotope effect. This strongly suggests that this motion in RNase $A$ is a correlated process. The proton inventory data additionally provide evidence that a single proton is involved in this dynamic. An alternative explanation, where a number of more complicated multiproton transfers with many small additive effects in the reactant state

Journal of the American Chemical Society, Vol 128, No. 24 (May 2006): pg. 7724-7725. DOI. This article is (C) American Chemical Society and permission has been granted for this version to appear in e-Publications@Marquette. American Chemical Society does not grant permission for this article to be further copied/distributed or hosted elsewhere without the express permission from American Chemical Society. 
that can fortuitously offset the transition state contribution, is theoretically possible. ${ }^{16}$ In the absence of additional evidence to the contrary, the simplest, one-proton mechanism is the best explanation of the experimental data.

This striking similarity of the solvent isotope effect for $k_{\text {cat }}$ and $k_{\text {ex }}$ supports the notion that enzyme flexibility and enzyme activity are tightly coupled and that both the rate limitation to the enzyme reaction and conformational motion are the same process dependent upon the same number and type of proton transfers in the transition state. The magnitude of the isotope effect suggests that this proton is likely bridging the reacting groups in the transition state. This bridging proton could be a component of a water molecule in which the other nonbridging proton is not altered in the transition state, such that it has a fractionation factor of unity resulting in no net contribution of this second proton to the observed isotope effect. On the basis of the $\mathrm{pH}$ dependence of this conformational motion (not shown), we reason that this process involves the side chain of a histidine residue.

The amazing ability of enzymes to increase the rate of chemical reactions results from a combination of many factors. Among these is the innate ability of enzymes to change shape as the reaction coordinate develops. Characterization of these motions, therefore, represents a necessary element for elucidation of enzyme-catalyzed reactions. The studies described here indicate that the rate of this conformational rearrangement for this highly efficient enzyme depends primarily on the transfer of a single proton.

\section{Acknowledgment}

J.P.L. thanks the NSF for a CAREER award and the Alfred P. Sloan Foundation for funding. We thank Professor Ken Wiberg for helpful suggestions.

\section{Supporting Information Available}

Experimental methods for the NMR experiments, location of flexible residues, CPMG dispersion curves, and a table summarizing the CPMG results. This material is available free of charge via the Internet at http://pubs.acs.org. 
NOT THE PUBLISHED VERSION; this is the author's final, peer-reviewed manuscript. The published version may be accessed by following the link in the citation at the bottom of the page.

\section{References}

${ }^{1}$ Radzicka, A.; Wolfenden, R. Science 1995, 267, 90-93.

${ }^{2}$ Knowles, J. R.; Albery, W. J. Acc. Chem. Res. 1977, 10, 105-111.

${ }^{3}$ Cole, R.; Loria, J. P. Biochemistry 2002, 41, 6072-6081.

${ }^{4}$ Eisenmesser, E. Z.; Bosco, D. A.; Akke, M.; Kern, D. Science 2002, 295, $1520-1523$.

${ }^{5}$ Williams, J. C.; McDermott, A. E. Biochemistry 1995, 34, 8309-8319.

${ }^{6} \mathrm{Lu}$, H. P.; Xun, L.; Xie, X. S. Science 1998, 282, 1877-1882.

${ }^{7}$ Loria, J. P.; Rance, M.; Palmer, A. G. J. Am. Chem. Soc. 1999, 121, 2331-2332.

${ }^{8}$ Millet, O. M.; Loria, J. P.; Kroenke, C. D.; Pons, M.; Palmer, A. G. J. Am. Chem. Soc. 2000, 122, 2867-2877.

${ }^{9}$ Hammes, G. G. Biochemistry 2002, 41, 8221-8228.

${ }^{10}$ Thompson, J. E.; Kutateladze, M. C.; Venegas, F. D.; Messmore, J. M.; Raines, R. T. Bioorg. Chem. 1995, 23, 471-481.

${ }^{11}$ Beach, H.; Cole, R.; Gill, M.; Loria, J. P. J. Am. Chem. Soc. 2005, 127, 9167-9176.

${ }^{12}$ Kovrigin, E. L.; Loria, J. P. Biochemistry 2006, 45, 2636-2647.

${ }^{13}$ Park, C.; Raines, R. T. Biochemistry 2003, 42, 3509-3518.

${ }^{14}$ Butler, J. A. V.; Hornel, J. C. J. Chem. Soc. 1936, 1361-1366.

${ }^{15}$ Matta, M. S.; Vo, D. T. J. Am. Chem. Soc. 1986, 108, 5316-5318.

${ }^{16}$ Kresge, A. J. J. Am. Chem. Soc. 1973, 95, 3065-3067.

Journal of the American Chemical Society, Vol 128, No. 24 (May 2006): pg. 7724-7725. DOI. This article is (C) American Chemical Society and permission has been granted for this version to appear in e-Publications@Marquette. American Chemical Society does not grant permission for this article to be further copied/distributed or hosted elsewhere without the express permission from American Chemical Society. 